\title{
Recent insights into nanotechnology development for detection and treatment of colorectal cancer
}

\author{
This article was published in the following Dove Press journal: \\ International Journal of Nanomedicine \\ 2 June 2016 \\ Number of times this article has been viewed
}

\section{Buddolla Viswanath ${ }^{\prime}$ \\ Sanghyo Kim' \\ Kiyoung Lee ${ }^{2}$}

'Department of Bionanotechnology, Gachon University, Gyeonggi-Do, ${ }^{2}$ Division of Endocrinology and

Metabolism, Gachon University Gil

Hospital, Incheon, Republic of Korea
Correspondence: Kiyoung Lee Division of Endocrinology and Metabolism, Gachon University Gil Hospital, Incheon 405-760, Republic of Korea

Email kylee@gilhospital.com

Sanghyo Kim

Department of Bionanotechnology, Gachon University, San 65, Bokjeong-

Dong, Sujeong-Gu, Seongnam-Si, Gyeonggi-Do 46I-70I, Republic of Korea Tel +8231 7508554

Emailsamkim@gachon.ac.kr

\begin{abstract}
The global incidence of colorectal cancer (CRC) is 1.3 million cases. It is the third most frequent cancer in males and females. Most CRCs are adenocarcinomas and often begin as a polyp on the inner wall of the rectum or colon. Some of these polyps become malignant, eventually. Detecting and removing these polyps in time can prevent CRC. Therefore, early diagnosis of CRC is advantageous for preventive and instant action interventions to decrease the mortality rates. Nanotechnology has been enhancing different methods for the detection and treatment of CRCs, and the research has provided hope within the scientific community for the development of new therapeutic strategies. This review presents the recent development of nanotechnology for the detection and treatment of CRC.
\end{abstract}

Keywords: colorectal cancer, nanotechnology, detection, treatment, targeted therapy

\section{Introduction}

Colorectal cancer (CRC) is a severe health problem and has the third highest incidence among the tumor-causing conditions that affect the populations of developed and developing countries. ${ }^{1}$ This cancer is a main reason of morbidity and death in the populations of Western countries. ${ }^{2}$ Generally, CRC occurs due to certain routine factors and increasing age, with only marginal cases resulting from fundamental genetic disorders. ${ }^{3,4}$ It mostly originates in the lining of the bowel and can migrate into the bowel wall and muscle layers beneath if not treated properly. ${ }^{5}$ In addition, there are environmental and genetic factors that can interact in different ways to potentiate carcinogenesis. ${ }^{4}$ Four central theories regarding the pathogenesis of CRC have been established. First, genetic and epigenetic variations that trigger colon cancer formation promote CRC. Second, the cancer emerges through a multistep succession at both the morphological and the molecular levels. Third, loss of genomic stability is an important molecular step in cancer formation. Fourth, hereditary cancer syndromes usually correspond to germ line forms of important genetic defects, for which somatic occurrences drive the appearance of infrequent colon cancers. ${ }^{6}$ Figure 1 illustrates different aspects of CRC, which offer broad focal points for studies and research explorations. In vitro studies have assisted to describe the scientific knowledge base regarding the incidence of CRC and the mechanisms that maintain its progression and support the spread of the disease. Clinical trials and studies have presented insights into disease management and patient care. Animal modeling provides a significant bridge between in vitro and in vivo studies (Figure 1). Our perceptive of CRC in terms of origination, genesis, initiation, and progression continues to improve. Although several factors contribute and influence the initiation and progression of the disease, the number of potential targets continues to increase. ${ }^{7}$ This targeting potential will eventually lead to 


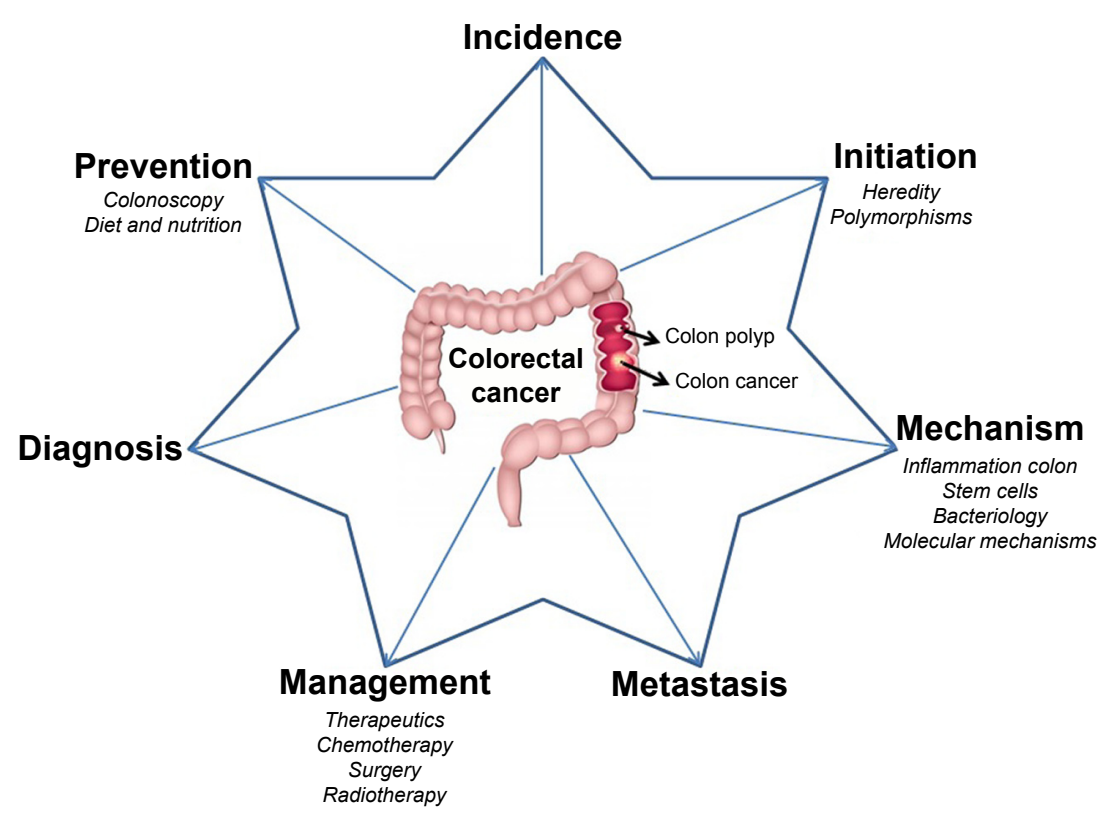

Figure I Aspects of colorectal cancer that offer broad focal points for studies and research investigations.

the progress of effective strategies for the management of the disease and will translate into better treatments for patients. Many decades of research have been directed at developing novel strategies in cancer research, particularly in the areas of diagnosis, enabling earlier cancer therapy to reduce cancer mortality. Therefore, prevention, particularly primary prevention, is an efficient way of addressing the challenging issues of cancer, because many cancers can be prevented based on our current knowledge of risk factors. In addition, preventive measures should be cost-effective, and its effects should not be limited to high-risk subjects but should extend to the entire population. ${ }^{8}$ Nanotechnology has opened up the way to the engineering of novel organized materials capable of improved performances in the detection and treatment of cancer. It has broad application prospects in the diagnosis and treatment of CRC and other cancers. ${ }^{4}$ Nanotechnologies applied to CRC include nanoparticle (NP)-based specific identification of tumors and cancer biomarkers, biologically targeted contrast agents, drug delivery systems, and novel treatment approaches. Recently, nanotechnologies have gained global consideration due to their potential to improve the current standards and techniques for the diagnosis and treatment of CRC. The current review discusses the recent insights into nanotechnology development for the detection and treatment of CRC.

\section{Stages of CRC}

The stage of a cancer, which describes the extent of the cancer in human body, is one of the most significant factors in deciding which treatment to use and how successful the treatment might be. ${ }^{9}$ Table 1 explains the different stages of CRC. In stage 0 , abnormal cells originate from the colonic wall mucosa. These unusual cells may become cancerous and spread. In stage I, cancer has formed in the mucosa of the colon wall and has extended to the submucosa. Stage II colon cancer is divided into stages IIA, IIB, and IIC. Stage III colon cancer is divided into stages IIIA, IIIB, and IIIC. Finally, stage IV colon cancer is divided into stages IVA and IVB. ${ }^{10,11}$ Table 1 provides the descriptions of all these stages. Per recent investigations, 5-year survival rates are $>90 \%$ for stage I CRC and $<10 \%$ for stage IV CRC. ${ }^{12}$ Lifestyle-related threats include obesity, physical inactivity, eating more quantities of processed or red meat, alcohol addiction, long-term smoking, and a diet with insufficient vegetables and fruits. In addition, family and/or personal history of CRC and an individual history of type 2 diabetes, chronic inflammatory bowel disease, or genetic disease like Lynch syndrome or familial adenomatous polyposis has been connected with augmented risk. ${ }^{13}$ In broad spectrum, stages 0, I, II, and III are often curable with surgery. But, many patients with stage III CRC and a few with stage II receive chemotherapy after surgery in order to amplify the chance of abolishing the disease. CRC patients with stages II and III also receive radiation therapy with chemotherapy either before or after surgery. ${ }^{14}$ Stage IV CRC is not often curable, but it is treatable and the growth of the cancer and the symptoms of the disease can be managed. ${ }^{15}$ In addition, clinical trials are also a treatment selection for each stage. ${ }^{16}$ 
Table I Different stages of colorectal cancer and their descriptions

\begin{tabular}{|c|c|}
\hline Stage & Description \\
\hline 0 & Early stage of colorectal cancer; also known as carcinoma in situ or intramucosal carcinoma \\
\hline I & The cancer has grown through the muscularis mucosa into the submucosa and may also have grown into the muscularis propria \\
\hline IIA & The cancer has spread through the muscular layer of the colon wall to the serosa (outermost layer) of the colon wall \\
\hline IIB & The cancer has spread through the serosa (outermost layer) of the colon wall but has not spread to nearby organs \\
\hline IIC & The cancer has spread through the serosa (outermost layer) of the colon wall to nearby organs \\
\hline IIIA & $\begin{array}{l}\text { The cancer has spread through the mucosa of the colon wall to the submucosa and may have spread to the muscular layer of } \\
\text { the colon wall. It has spread to at least one but not more than three nearby lymph nodes or cancer cells that have formed in } \\
\text { tissues near the lymph nodes, or; } \\
\text { The cancer has spread through the mucosa of the colon wall to the submucosa and has spread to at least four but not more } \\
\text { than six nearby lymph nodes }\end{array}$ \\
\hline IIIB & $\begin{array}{l}\text { The cancer has spread through the muscular layer of the colon wall to the serosa or has spread through the serosa but not to } \\
\text { nearby organs. It has spread to at least one but not more than three nearby lymph nodes or cancer cells have formed in tissues } \\
\text { near the lymph nodes, or; } \\
\text { The cancer has spread to the muscular layer of the colon wall or to the serosa of the colon wall. It has spread to at least four } \\
\text { but not more than six nearby lymph nodes, or; } \\
\text { The cancer has spread through the mucosa (innermost layer) of the colon wall to the submucosa and may have spread to the } \\
\text { muscular layer of the colon wall. It has spread to seven or more nearby lymph nodes }\end{array}$ \\
\hline IIIC & $\begin{array}{l}\text { The cancer has spread through the serosa of the colon wall but has not spread to nearby organs. It has spread to at least four } \\
\text { but not more than six nearby lymph nodes, or; } \\
\text { The cancer has spread through the muscular layer of the colon wall to the serosa or has spread through the serosa but not } \\
\text { spread to nearby organs. It has spread to seven or more nearby lymph nodes, or; } \\
\text { The cancer has spread through the serosa of the colon wall and spread to nearby organs. It has spread to one or more nearby } \\
\text { lymph nodes, or cancer cells have formed in tissues near the lymph nodes }\end{array}$ \\
\hline IVA & $\begin{array}{l}\text { The cancer may have spread through the colon wall and spread to nearby organs or lymph nodes. It has spread to one organ } \\
\text { that is not near the colon, such as liver, lung, or ovary or to a distant lymph node }\end{array}$ \\
\hline IVB & $\begin{array}{l}\text { The cancer may have spread through the colon wall and spread to nearby organs or lymph nodes. It has spread to more than } \\
\text { one organ that is not near the colon or into the lining of the abdominal wall }\end{array}$ \\
\hline
\end{tabular}

\section{Existing methods to screen and detect CRC}

Screening is the strategy for identifying the presence of cancer in asymptomatic individuals. A number of tests can be used to screen for CRCs. Normally, colonoscopy is the general screening method for $\mathrm{CRC}$ and allows examining the entire rectum and colon of a patient for polyps or cancer. ${ }^{17}$ This test also allows for the removal of polyps. However, the process is expensive and unpleasant. Computed tomographic (CT) colonography or virtual colonoscopy is another choice for patients who cannot go through a standard colonoscopy due to the risk of anesthesia or for persons with an obstruction in the colon, which prevents a full examination. ${ }^{18}$ In sigmoidoscopy, a flexible tube, with a light at the end, is inserted into the rectum and lower colon to check for polyps, cancer, and other abnormalities. ${ }^{19}$ For patients who cannot undergo colonoscopy, an enema containing barium is administered, which highlights the outline of the colon and rectum on the $\mathrm{X}$-ray images. Stool DNA tests analyze the DNA from a person's stool sample to screen for CRC. These screening tests vary with respect to their degree of invasiveness, patient expediency, preparation requirement, amount of colon evaluated, and test limitations. Table 2 provides the list of detection methods for CRCs and their merits and demerits. In addition to these general methods, the CellSearch ${ }^{\circledR}$ assay (Janssen Diagnostics, LLC, South Raritan, NJ, USA) is the only US Food and Drug Administration-cleared circulating tumor cell (CTC) diagnostic technology for metastatic CRC along with other cancers like prostate and breast cancers. Enumeration of CTCs by the CellSearch ${ }^{\circledR}$ system provides predictionrelated information in metastatic $\mathrm{CRC}$, irrespective of the metastatic site. ${ }^{20}$ CellSearch $^{\circledR}$ assay harvests CTCs with anti-epithelial cell adhesion molecule (anti-EpCAM)-coated magnetic beads, and the subsequent immunocytochemistry process helps to identify CTCs (DAPI+/cytokeratin, $\mathrm{CK}+$ / CD45-) from nonspecifically captured white blood cells (DAPI+/CK-/CD45+). Recently, several new systems like MagSweeper, IsoFlux, Cynvenio, magnetic sifters, VerIFAST, and AdnaGen/Qiagen have been developed to further improve the detection speed and efficiency. ${ }^{21}$ However, identifying CTCs in peripheral blood has been proven to be more difficult than expected, due to very minute quantity of CTCs in blood and lack of technology with sufficiently high sensitivity and specificity. In addition, the CellSearch ${ }^{\circledR}$ system is very expensive and difficult to operate at the point of care. Therefore, the development of alternative sensitive, 
Table 2 Merits and demerits of different screening methods of CRC

\begin{tabular}{|c|c|c|c|}
\hline Method & Description & Merits & Demerits \\
\hline Colonoscopy & $\begin{array}{l}\text { It allows for the examination of the entire } \\
\text { inner lining of the rectum and colon of a } \\
\text { patient for polyps or cancer }\end{array}$ & $\begin{array}{l}\text { It detects most small polyps and } \\
\text { almost all large polyps and cancers, } \\
\text { substantially reducing the risk of } \\
\text { development of and death from CRC }\end{array}$ & $\begin{array}{l}\text { It requires sedation } \\
\text { It may lead to serious bleeding or a tear } \\
\text { of the intestinal wall }\end{array}$ \\
\hline $\begin{array}{l}\text { CT } \\
\text { colonography }\end{array}$ & $\begin{array}{l}\text { It uses a CT scanner to capture images } \\
\text { of the entire colon. These images are } \\
\text { two- and three-dimensional and are } \\
\text { reconstructed to allow a radiologist to } \\
\text { determine if polyps or cancers are present }\end{array}$ & $\begin{array}{l}\text { It does not require sedation } \\
\text { It is noninvasive, the entire bowel } \\
\text { can be examined, and abnormal areas } \\
\text { (such as adenomas) can be detected as } \\
\text { well as with traditional colonoscopy }\end{array}$ & $\begin{array}{l}\text { It requires a bowel prep to clean out } \\
\text { the colon } \\
\text { It may detect abnormalities other than } \\
\text { polyps or cancer in the colon/rectum }\end{array}$ \\
\hline Sigmoidoscopy & $\begin{array}{l}\text { It allows a physician to directly view the } \\
\text { lining of the rectum and the lower part of } \\
\text { the colon }\end{array}$ & $\begin{array}{l}\text { It identifies polyps and cancers in the } \\
\text { descending colon and rectum with a } \\
\text { high degree of accuracy }\end{array}$ & $\begin{array}{l}\text { It cannot detect polyps or cancers that } \\
\text { are located on the right side (such as the } \\
\text { cecum, ascending colon hepatic flexure, } \\
\text { or some of the transverse colon) }\end{array}$ \\
\hline $\begin{array}{l}\text { Stool tests } \\
\text { (FIT or FOBT) }\end{array}$ & $\begin{array}{l}\text { These are kits that can detect abnormal } \\
\text { blood or DNA markers. FOBT uses guaiac } \\
\text { to detect blood. FIT, on the other hand, } \\
\text { uses antibodies to detect blood in the stool }\end{array}$ & $\begin{array}{l}\text { Cleansing of the colon is not required } \\
\text { Samples can be collected at home } \\
\text { The cost is low compared with other } \\
\text { bowel cancer screening tests }\end{array}$ & It cannot detect nonbleeding tumors \\
\hline $\begin{array}{l}\text { Double- } \\
\text { contrast } \\
\text { barium enema }\end{array}$ & $\begin{array}{l}\text { This is a barium sulfate suspension that } \\
\text { is injected with air into the rectum via a } \\
\text { flexible tube; X-ray images are then taken }\end{array}$ & $\begin{array}{l}\text { This test generally allows the } \\
\text { doctor to view the rectum and the } \\
\text { entire colon } \\
\text { Complications are rare } \\
\text { Sedation is not necessary }\end{array}$ & $\begin{array}{l}\text { The test may not detect some small } \\
\text { polyps and cancers } \\
\text { A thorough cleansing of the colon is } \\
\text { necessary before the test } \\
\text { False-positive results are possible }\end{array}$ \\
\hline
\end{tabular}

Abbreviations: CRC, colorectal cancer; CT, computed tomography; FIT, fecal immunochemical test; FOBT, fecal occult blood test; prep, preparation.

speedy, specificity, and low-cost methods for CRC screening and detection is important for cancer prognosis. Novel tests based on new biomarkers, new imaging modalities, or variations of the existing methods continue to emerge for the screening and/or detection of CRC; however, evaluation of these options presents a challenge. It has been observed that novel diagnostic tests regularly enter practice without confirmation of the improved results. ${ }^{22}$

\section{Existing methods to treat CRC}

At present, there are many treatments available for CRC based on CRC stage. Table 3 summarizes the advantages and disadvantages of some of them. This section is included to enable readers to become more aware of some of the different treatment options. Surgery is the most common treatment for $\mathrm{CRC}$ and is often called surgical resection. It is an important first line of defense against any cancer, particularly if the tumor is well defined. ${ }^{23,24}$ In CRC, part of the healthy colon or rectum and nearby lymph nodes will also be removed. Besides surgical resection, surgical options for CRC include laparoscopic surgery, colostomy for rectal cancer, radiofrequency ablation, and so on. In general, the side effects of surgery include pain and tenderness in the area of operation along with constipation or diarrhea. Radiation therapy is commonly used for treating rectal cancer because this tumor tends to persist near where it initially started. A radiation therapy schedule generally consists of a specific number of treatments given over a set period of time. ${ }^{25}$ Side effects from radiation therapy may include fatigue, mild skin reactions, stomach upset, and so on. It may also cause bloody stools from bleeding through the rectum or blockage of the bowel. In addition, sexual problems, as well as infertility in both men and women, may occur after radiation therapy. Chemotherapy is the use of drugs to demolish cancer cells, normally by stopping the ability of cancer cells to grow and divide. Currently, several drugs are approved to treat CRC. ${ }^{26}$ Chemotherapy may cause nausea, vomiting, diarrhea, neuropathy, or mouth sores. Targeted therapy is a treatment that targets the specific genes of the cancer or the tissue environment. This type of treatment blocks the growth and spread of cancer cells while limiting damage to healthy cells. To find the most effective treatment, we need to run tests to identify the genes, proteins, and other factors in a patient's tumor. For CRC, anti-angiogenesis therapy, epidermal growth factor receptor (EGFR) inhibitor therapy are options. The side effects of the targeted treatments include rashes on the face and upper body.

\section{Applications of nanotechnology in screening, detection, and treatment of CRC}

More than four decades ago, foundations were laid down for nanotechnologies to fabricate diagnostic and therapeutic 
Table 3 Merits and demerits of various existing methods of treatment of CRC

\begin{tabular}{|c|c|c|c|}
\hline Method & Description & Merits & Demerits \\
\hline Surgery & $\begin{array}{l}\text { Surgery is the most common treatment } \\
\text { for CRC and is often called surgical } \\
\text { resection. It includes laparoscopic } \\
\text { surgery, colostomy for rectal cancer, } \\
\text { and radiofrequency ablation }\end{array}$ & $\begin{array}{l}\text { Surgical removal of a tumor is } \\
\text { an important first line of defense } \\
\text { against CRC, particularly if the } \\
\text { tumor is well defined }\end{array}$ & $\begin{array}{l}\text { Surgery has been shown to increase the risk of } \\
\text { death by metastasis in certain cancer patients } \\
\text { by simple mechanical disruption of tumor } \\
\text { integrity. Pain and tenderness in the area of } \\
\text { the operation are other general demerits }\end{array}$ \\
\hline $\begin{array}{l}\text { Radiation } \\
\text { therapy }\end{array}$ & $\begin{array}{l}\text { Radiation therapy is the use of high- } \\
\text { energy X-rays to destroy cancer cells }\end{array}$ & $\begin{array}{l}\text { For CRC, radiation therapy may } \\
\text { be used before surgery, called } \\
\text { neoadjuvant therapy, to shrink the } \\
\text { tumor, so that it will be easier to } \\
\text { remove. It may also be used after } \\
\text { surgery to destroy any remaining } \\
\text { cancer cells. Both the approaches } \\
\text { have worked to treat this disease }\end{array}$ & $\begin{array}{l}\text { The sensitivity to ionizing radiation differs } \\
\text { from one subject to another, with respect to } \\
\text { the amount of damage caused to healthy cells. } \\
\text { In those with increased sensitivity to radiation } \\
\text { damage, exposure to radiation therapy can } \\
\text { cause sufficient DNA damage to initiate the } \\
\text { development of further neoplasms }\end{array}$ \\
\hline Chemotherapy & $\begin{array}{l}\text { Chemotherapy is the use of drugs to } \\
\text { destroy cancer cells, which usually } \\
\text { stops the ability of cancer cells to grow } \\
\text { and divide }\end{array}$ & $\begin{array}{l}\text { Chemotherapy is a well- } \\
\text { recognized treatment modality }\end{array}$ & $\begin{array}{l}\text { Chemotherapy may cause vomiting, nausea, } \\
\text { diarrhea, neuropathy, or mouth sores }\end{array}$ \\
\hline $\begin{array}{l}\text { Targeted } \\
\text { therapy }\end{array}$ & $\begin{array}{l}\text { Targeted therapy is a treatment that } \\
\text { targets the cancer-specific genes or } \\
\text { proteins or the tissue environment that } \\
\text { contributes to the growth and survival } \\
\text { of cancer }\end{array}$ & $\begin{array}{l}\text { This type of treatment blocks the } \\
\text { growth and spread of cancer cells } \\
\text { while limiting damage to healthy } \\
\text { cells }\end{array}$ & $\begin{array}{l}\text { The side effects of targeted treatments can } \\
\text { include a rash on the face and upper body }\end{array}$ \\
\hline Immunotherapy & $\begin{array}{l}\text { Immunotherapies used for treating } \\
\text { CRC include monoclonal antibodies, } \\
\text { immune modulators, cancer vaccines, } \\
\text { cytokines, and adjuvants }\end{array}$ & $\begin{array}{l}\text { Uses the body's own immune } \\
\text { system. Fewer side effects and } \\
\text { can improve long-term survival } \\
\text { by } 30 \%\end{array}$ & $\begin{array}{l}\text { Some immunotherapy drugs have severe side } \\
\text { effects, high cost, and possible short-term } \\
\text { efficacy }\end{array}$ \\
\hline
\end{tabular}

Abbreviation: CRC, colorectal cancer.

agents in a more well-organized manner. ${ }^{27}$ Achieving this vision became more clearer and sensible over the last few years, with the rising numbers of nanodiagnostics and nanotherapeutics being commercialized or having reached the clinical stage. ${ }^{28}$ Several useful nanotechnological applications have been identified in cancer biology, including early detection of tumors and the development of treatment approaches that cannot be achieved using the existing conventional technologies. ${ }^{29}$ In fact, in certain cancers, nanometer-sized particles of diverse shapes and compositions have come out as promising and important new tools for CRC diagnosis, staging, and therapeutics..$^{30}$ Early detection of CRC is the key for prevention, and it has the ability to impact the long-term survival of patients with CRC. Here, we summarize the recent achievements of NPs that offered new prospects for the early detection and successful treatment of CRC.

\section{Applications of quantum dots}

Quantum dots (QDs) are semiconductor nanocrystals that fluoresce on excitation with light and have exceptional optical characteristics, including high brightness, resistance to photobleaching, and the ability to emit fluorescence at different wavelengths. Given the optical and chemical advantages of QDs, QD-based nanotechnology is an emerging platform for studying cancers including the CRC. ${ }^{31-33}$

In a recent study, researchers qualitatively analyzed the expression level of large external antigen in tissue samples from CRC patients using QD-based immunohistochemistry (QD-IHC) and conventional IHC. ${ }^{34}$ Compared with conventional IHC, QD-IHC offered several noticeable advantages for protein marker quantification. These included higher sensitivity, simpler operation, less human interference, and increased capability for simultaneous multifactor analysis, which would lead to more accurate clinical evaluations. Therefore, QD-IHC could be a substitute for conventional IHC in clinical applications. In addition, unlike the majority of other studies that primarily focus on marker detection in tissue sections using QD probes, QD-based immunocytochemistry combined with imaging quantitative analysis for the detection of large external antigen in living cells achieved results that were in agreement with those generated using flow cytometry. This result suggested that this method is for noninvasive molecular analysis of rare CTCs and provided a rationale for expanding the application of QD probes to clinical practice. ${ }^{34}$ In another study, a simple and highly sensitive 
technique was developed to detect aldo-ketoreductase family 1 member B10 (AKR1B10), a prognostic predictor and therapeutic target for CRC in the serum, using QDs with a high-fluorescence quantum yield against photo bleaching and size-controlled luminescence. ${ }^{35}$ This immunofluorescence assay to detect serum AKR1B10 using anti-AKR1B10conjugated $\mathrm{CdTe} / \mathrm{CdS} \mathrm{QDs}$ is a promising approach for the early prediction of CRC. This technique was simple and fast with high sensitivity and specificity.

Carbary-Ganz et $\mathrm{al}^{36}$ developed a technology in which optical coherence tomography/laser-induced fluorescence dual-modality imaging allows for slightly invasive, nondestructive endoscopic visualization of CRC. ${ }^{36}$ This strategy enables simultaneous longitudinal tracking of morphological (optical coherence tomography) and biochemical (fluorescence) alterations during $\mathrm{CRC}$ development and progression. In the carcinogen-treated mice, QDot655 targeted to vascular endothelial growth factor receptor 2 (QD655-VEGFR2) localized to the colon and offered a considerably high contrast between the diseased and healthy tissue with high sensitivity and specificity ex vivo. ${ }^{36}$ In another study, researchers developed an exceptional cell-targeted, paramagnetic-fluorescent double-signal molecular nanoprobe (GdDTPA·BSA@QDs$\mathrm{PcAb}$ ) for in vivo magnetic resonance imaging (MRI) diagnosis and subsequent biopsy of CRC. ${ }^{37}$ These multipurpose GdDTPA·BSA@QDs-PcAb nanoprobes were synthesized by surface engineering of QDs with DTPA.BSA-Gd3 ${ }^{+}$macromolecule complex under ultrasonication conditions. The resulting GdDTPA·BSA@QDs exhibit excellent colloidal constancy with fine hydrodynamic size in a broad array range of $\mathrm{pH}$ values and ionic strengths. They also exhibit much higher transverse relaxivity and longitudinal relaxivity in water than commercial Gd-DTPA solutions. ${ }^{37}$ In vivo MRI revealed GdDTPA·BSA@QDs-PcAb to be a promising candidate for use in CRC contrast-enhanced MRI diagnosis. Biodistribution results showed gradual clearance of the nanoprobes from the body via biliary (hepatobiliary) excretion. No obvious in vitro or in vivo toxicity was observed in the MTT assay or toxicity studies, respectively. Based on these experimental evidences, the GdDTPA·BSA@QDs-PcAb nanoprobes show great potential for CRC tumor-targeted MRI and tumor tissue biopsy analysis. ${ }^{37}$

Gazouli et $\mathrm{al}^{38}$ assessed the CRC-targeting ability of bevacizumab-conjugated QDs in vitro and in vivo. In the in vitro studies, immunocytochemical data confirmed strong and specific binding of the QD-bevacizumab complex to the cells. In vivo fluorescence imaging showed improvement of the tumor-specific signal following injection of the QDs.
This study successfully detected VEGF-expressing tumors using QDs-bevacizumab nanoprobes in vitro and in vivo, and these consequences represent a significant advancement in VEGF-targeted noninvasive imaging in clinical practice. ${ }^{38}$ In another study, Carbary-Ganz et al ${ }^{39}$ successfully labeled CRC in vivo using QDs targeted to VEGFR2. QDs with emission centered at $655 \mathrm{~nm}$ were bioconjugated to anti-VEGFR2 antibodies through streptavidin/biotin linking. ${ }^{39}$ The resulting QD655-VEGFR2 contrast agent was functional in vivo and localized to the colon of azoxymethane-treated mice following lavage and incubation. This QD655-VEGFR2 contrast agent significantly enhanced the contrast between diseased and normal tissues. Specificity was assessed by observing an inappropriate increase in contrast, when labeling colons of azoxymethane-treated mice with QDs bioconjugated to isotype control antibodies and by labeling the colons of saline-treated mice (control). This contrast agent shows great possibility for in vivo endoscopic imaging of the colon. ${ }^{39}$

Using the subtractive Cell-SELEX technology under selective conditions, $\mathrm{Li}$ et $\mathrm{al}^{40}$ produced a panel of seven aptamers (Apts) that specifically bind metastatic CRC cells (LoVo cells) and some other metastatic cancer cell lines with high affinity, thereby offering broad-spectrum specific recognition of metastatic cancer cells. This study demonstrated that Apts selected from single Cell-SELEX can be individually functionalized for various purposes according to the biochemical properties of the targets, thereby increasing the advantages of the Cell-SELEX approach. The receptortargeting Apt W14 was used as a targeted carrier for specific delivery of doxorubicin to target cells in order to remarkably decrease the cytotoxicity of this drug. The nonmembrane receptor-binding Apt W3 conjugated to a QD was used as a molecular probe for targeted imaging of metastatic cancer cell lines, metastatic tumor-bearing tissue sections, and formalin-fixed paraffin-embedded specimens from CRC patients. ${ }^{40}$ These two Apts (W14 and W3) may be adopted for combinational diagnostic and therapeutic applications as they target the same cells. In addition, the seven Apts investigated in this study exhibited no cross recognition of their individual targets. This finding suggested that these Apts can be used in combination for multitarget cancer cell imaging and multitarget drug therapy to overcome drug resistance, gaining high detection sensitivity, and attaining good treatment effectiveness for metastatic cancer. ${ }^{40}$ Therefore, QDs are a technological advancement that can revolutionize CRC diagnosis and treatment. As stated earlier, QDs are now widely used for the detection of cancer biomarkers and cancer cell invasion and for focusing on the tumor environment. Furthermore, they 
represent a new strategy for deeper analysis of CRC tumor heterogeneity, as well as showing promise for the diagnosis and treatment of CRC.

\section{Applications of iron oxide nanocrystals}

Iron oxide NPs have the dual ability to act as both magnetic and photothermal agents and have been approved for human use as MRI contrast agents. They also have excellent biodegradability in vivo, and the iron ions they release upon dissolution can be assimilated by the body through a tightly regulated physiological process. ${ }^{41}$ Kuo et $\mathrm{al}^{42}$ fabricated smart multifunctional magnetic nanovehicles encapsulating anticancer drugs and an antibody-targeting peptide AP-1 (MPVA-AP1). ${ }^{42}$ In this study, the magnetic nanovehicles with consistent sizes and dispersed in aqueous solution displayed good hemocompatibility and no toxicity toward L929 fibroblasts, which showed their potential for applications in therapeutics. Using a simple synthesis method, that is, the double-emulsion method, the researchers observed considerable encapsulation of both hydrophilic and hydrophobic lowmolecular-weight drugs and protein-like drugs. Furthermore, the antibody-targeting peptide AP-1 was immobilized on the surface of the magnetic nanovehicles, and the immobilization was confirmed through electron spectroscopy. A CRC cell (CT26-IL4R $\alpha$ ) test revealed that the AP-1-bound nanovehicles (MPVA-AP1) exhibited outstanding targeting and selectivity. A stable storage test confirmed near-zero leakage of the encapsulated drugs in the absence of the magnetic stimulus. In contrast, the doxorubicin-loaded nanovehicles ruptured upon high-frequency magnetic field treatment, that is, rapid and accurate controlled release. Moreover, in vivo studies established that the magnetic nanovehicles displayed obvious thermotherapeutic and chemotherapeutic effects. Thus, smart magnetic nanovehicles, such as MPVA-AP1, have significant potential for targeted doses and accurate controlled release in anticancer applications. ${ }^{42}$

Esmaelbeygi et $\mathrm{al}^{43}$ demonstrated the effectiveness of polylactide-co-glycolic acid (PLGA) NPs as a 5-fluorouracil (5-FU) carrier with and without an iron oxide core and hyperthermia at the point of DNA damage in a spheroid culture model of HT-29 colon cancer cell lines by alkaline comet assay. ${ }^{43}$ In their study, the cells treated with a combination of hyperthermia and 5-FU or NPs as 5-FU carriers showed more DNA damage than the controls. The degree of DNA damage following the treatment with 5-FU-loaded NPs and hyperthermia was considerably more than that for 5-FU and hyperthermia. Between 5-FU-loaded NPs with and without the iron oxide core, the NPs with the iron oxide core in combination with hyperthermia induced more DNA damage than those without the iron oxide core. As per this study, hyperthermia is a harmful agent, and NPs are efficient delivery vehicles of drugs to CRCs. The iron oxide-filled NPs increased the effect of hyperthermia and could be highly useful in the treatment of CRCs.

Yang et $\mathrm{al}^{44}$ synthesized magnetic nanoparticles coated with antibodies against carcinoembryonic antigen (CEA) and studied different characteristics like particle size, particle suspension, bioactivity, and the constancy of biomagnetic NPs suspended in liquid. ${ }^{44}$ In addition, the characteristics of the CEA molecules in serum were studied, and the assay method used was immunomagnetic reduction. Their results showed that the effects of common materials in serum that interfere with the detection of signals are not vital. The lower limit of detection was $0.21 \mathrm{ng} / \mathrm{mL}$, which is below the clinical threshold of $2.5 \mathrm{ng} / \mathrm{mL}$. The dynamic range for the assay of CEA molecules in serum was $2.5-500 \mathrm{ng} / \mathrm{mL}$. By quantifying serum CEA levels in 24 controls (normal) and $30 \mathrm{CRC}$ patients, the threshold for the serum-CEA concentration for CRC diagnosis was found to be $4.05 \mathrm{ng} / \mathrm{mL}$, which yields a clinical sensitivity of 0.90 and specificity of $0.87 .{ }^{44}$ In another study, researchers encapsulated the paclitaxel (PTX) and super-paramagnetic iron oxide (SPIO) inside the core of PEALCa micelles and used these for potential cancer therapy. ${ }^{45}$ Drug release study showed that the PTX in the micelles was released faster at $\mathrm{pH} 5.0$ lower than the neutral $\mathrm{pH}$. Cell culture experiments revealed that the PTX-SPIO-PEALCa micelle was successfully internalized by human CRC LoVo cells, and PTX was likely entrenched within lysosomal compartments. In addition, the accuracy of delivery to LoVo cells was confirmed in vivo by MRI and histological analysis. Furthermore, successful suppression of CRC LoVo cell growth was confirmed. Their observations established that the PTX-SPION-loaded pH-sensitive micelles were a capable MRI-visible drug-release system for CRC therapy. ${ }^{45}$

Mannucci et $\mathrm{al}^{46}$ tested magnetosomes (MNs), magnetic NPs produced by magnetotactic bacteria, to develop novel therapeutic strategies for neoplastic diseases. ${ }^{46}$ They extracted MNs from the gram-negative bacterium, Magnetospirillum gryphiswaldense, and tested their interactions with cellular elements and antineoplastic activity both in vitro and in vivo. In vitro studies executed on HT-29 cell cultures established strong uptake of MNs without any cytotoxicity. In vivo experiments were carried out on subcutaneous tumors in mice, and MNs were administered by direct injection into the 
tumor, and the tumors were monitored by MRI. Histological investigation showed fibrous and necrotic areas close to the MN injection sites in mice subjected to a total thermotherapy procedure. These observations, even though relating to a specific tumor model, might be helpful to further investigate the feasibility and efficacy of protocols based on magnetic fluid hyperthermia. In addition, magnetic nanoparticles naturally produced and extracted from bacteria appear to be appropriate candidates for applications in cancer therapy. ${ }^{46}$

He et al reported the covalent conjugation of lectin on $\mathrm{Fe}_{2} \mathrm{O}_{3} @ \mathrm{Au}$ core@shell NP (lectin- $\mathrm{Fe}_{2} \mathrm{O}_{3} @ \mathrm{Au} \mathrm{NP}$ ) for T2-weighted MRI and X-ray CT dual-modality imaging. ${ }^{47}$ The lectin- $\mathrm{Fe}_{2} \mathrm{O}_{3} @ \mathrm{Au}$ NPs are synthesized by combining lectins with the $\mathrm{Fe}_{2} \mathrm{O}_{3} @ \mathrm{Au}$ NP surfaces through bifunctional polyethylene glycol (PEG) NHS ester disulfide (NHS-PEGS-S-PEG-NHS) linkers. After the nonspecific adsorption places on the surface of NP are blocked by thiolated PEG (PEG-SH), the lectin- $\mathrm{Fe}_{2} \mathrm{O}_{3} @ \mathrm{Au}$ NPs showed exceptional stability in biological medium and imperceptible cytotoxicity. A sequence of both in vitro and in vivo trials performed for assessing the potential of three selected lectins (ConA, $\mathrm{RCA}$, and WGA)- $\mathrm{Fe}_{2} \mathrm{O}_{3} @ \mathrm{Au}$ NPs revealed that the lectin$\mathrm{Fe}_{2} \mathrm{O}_{3} @ \mathrm{Au}$ NPs could be used for dual mode MRI and CT imaging in vitro and also for MRI and CT imaging of CRC in vivo. The obtained results recommend that lectins could be used as tumor targeting ligands in NP-based contrast agents. $^{47}$

\section{Applications of PLGA nanoparticles/nanocells}

Biodegradable PLGA NPs have been used as carriers for peptides, proteins, nucleotides, vaccines, and drugs. These can help in protecting drug moieties from degradation and consequently ensure sustained release of drugs. ${ }^{48}$ NPs have also been extensively studied for their potential use in cancer therapy, particularly for CRC. For instance, curcumin-loaded PLGA NPs for colon delivery were successfully prepared using the emulsion-solvent evaporation technique. ${ }^{49}$ The use of the $2^{3}$ factorial design model enabled the development of an optimized curcumin-loaded PLGA-based nanoformulation using minimal raw material in a short time. Studies based on differential scanning calorimetry confirmed the presence of curcumin in an amorphous or disordered crystalline phase of molecular dispersion form or in a solid solution state in the polymer matrix. Fourier transform infrared studies confirmed that no substantial interactions occur between curcumin and PLGA. Transmission electron microscopy images of the optimized blank NPs (B-PNP ) and curcumin-loaded PLGA NPs
$\left(\mathrm{C}-\mathrm{PNP}_{9}\right)$ revealed that the NPs were discrete, nonaggregated, and spherical in shape and displayed good size distribution. The smaller size, sustained release, better colloidal stability in synthetic gastrointestinal fluids, long-term stability, and a considerably higher cellular uptake in HT-29 cells as compared with those of pure curcumin solution indicate that the optimized curcumin-loaded PLGA NP formulation (C-PNP ${ }_{9}$ ) has high potential as an initial platform for the further development of an efficient oral targeted drug-delivery system to the colon, especially if it is further functionalized with a mucoadhesive polymer or a specific targeting ligand. ${ }^{49}$

In another study, researchers prepared chitosan polymeric NPs by the solvent evaporation emulsification method, with varied ratios of polymer. ${ }^{50}$ They concluded that the NPs prepared by solvent evaporation emulsification using the polymer at the optimum ratio represents an approach for potentially successful delivery of the active pharmaceutical element to the colorectal tumors. ${ }^{50}$ Total health centre complex N-38 is a highly effective drug against many cancers, as it contains pharmaceutically active ingredients. However, the development of an optimal delivery system for SN-38 is challenging, owing to its low solubility and the presence of a labile lactone ring. Essa et $\mathrm{al}^{51}$ used $\mathrm{SN}-38$ encapsulated in poly(D,L-lactide-co-glycolide) NPs in their study to improve its cellular uptake, solubility, and stability. SN-38-loaded NPs prepared by the spontaneous emulsification solvent diffusion method have the ability to protect the active lactone ring of SN-38 against degradation under physiological conditions. They used the COLO-205 (colorectal adenocarcinoma) cell line to assess the effects of NPs on cytotoxicity and cellular uptake and found significantly decreased cell proliferation and apoptosis. Their results suggest that these SN-38-loaded NPs are a potentially desirable drug-delivery system to treat CRC. ${ }^{51}$

Polymeric NPs are known to assist the intracellular uptake of drugs to enhance their effectiveness, with lowest bioreactivity. In a study, researchers assessed cellular uptake and trafficking of PLGA NPs and chitosan (Chi)-covered PLGA NPs in human colorectal adenocarcinoma cells (COLO-205). ${ }^{52}$ Neither Chi-PLGA nor PLGA NPs were toxic to the assessed cells at concentrations of up to $2,500 \mu \mathrm{g} / \mathrm{mL}$. This study offered novel insights into the interaction of NPs with target cells, sustaining the use of NPs as new drug-delivery systems in cancer therapy. ${ }^{52}$ In another study, Tang et $\mathrm{a}^{53}$ prepared NPs loaded with 5-FU and investigated the feature of NPs and their role in peritoneal metastasis nodule pattern in colon cancer. They successfully synthesized antitumor NPs loaded with 5-FU, which had inhibitory effects on the CRC cell line 
and peritoneal disseminations in a nude mouse model. This might represent a new antitumor preparation for peritoneal metastases, with intense clinical applications.

In a study, researchers proposed the use of PLGA-based polymeric oil-core nanocapsules (NCs) for curcumin loading and delivery to CRC in mice after systemic injection. ${ }^{54}$ Their findings specify that castor oil-core PLGA-based NCs provide elevated drug-loading efficiency and that the curcuminloaded NCs are more effective against CT26 cells than the free drug and apply therapeutic activity in vitro, leading to apoptosis and blockade of the cell cycle. Additionally, the formulated NCs have a better half-life in blood circulation than that of the non-PEGylated NCs and accumulate in the subcutaneous CT26 tumors in mice after complete administration. The obtained results are established by optical and single-photon emission CT/CT imaging. In addition, in vivo growth delay experiments were performed, and significantly smaller tumor volumes were observed than those in animals injected with empty NCs. This study demonstrates an immense potential of the formulated NC in treating CRC..$^{54}$ To enhance the effectiveness of drug delivery, active targeted nanotechnology-based drug-delivery systems are receiving significant consideration, as they have the ability to minimize the side effects, reduce the toxicity, and elevate the effectiveness of anticancer treatment. For instance, Li et $\mathrm{al}^{55}$ synthesized curcumin-loaded lipid-polymer-lecithin hybrid NPs (CUR-NPs) and functionalized them with RNA Apts against EpCAM for targeted delivery to colorectal adenocarcinoma cells. Their results demonstrated that the EpCAM Apt-functionalized CUR-NPs showed improved targeting and delivery of CUR to CRC cells. ${ }^{55}$

\section{Dendrimer applications}

Dendrimers are three-dimensional macromolecular structures that originate from a central core molecule and are bounded by the consecutive addition of branching layers. These structures show a high degree of molecular consistency, a fine molecular weight distribution, tunable size, in addition to shaping characteristics, along with multivalency. Altogether, these physicochemical properties with progressions in design of biodegradable backbones have conferred numerous applications to dendrimers in the development of nanopharmaceuticals. ${ }^{56-58}$ Xie et al hypothesized that the dual antibody conjugates may confer the advantage of capturing CTCs purposely as opposed by their single antibody counterparts. ${ }^{59}$ They established that the surface-functionalized dendrimers can be consecutively covered with two antibodies directed to surface biomarkers (EpCAM and Slex) of human colorectal CTCs. The dual antibody-coated dendrimers demonstrate a considerably improved specificity toward capturing CTCs in the presence of interfering blood cells and in both patient blood and nude mice administered the labeled CTCs compared to their single antibody-coated counterparts. In addition, the dual antibody-coated conjugates down-regulate the captured CTCs. This study provided the first theoretical confirmation of two antibodies that could be biocompatible conjugated to a nanomaterial to capture and down-regulate CTCs in vivo with the improved specificity. ${ }^{59}$ Furthermore, these findings provided the foundation for designing effective and safe nanomedicines for capturing and restraining CTCs and, for the first time, provided conceptual evidence for a new strategy for the prevention of cancer metastasis. ${ }^{59}$

Xie et al in another study reported a successful approach to specifically bind and capture HT29 cells by means of several Sialyl Lewis $\mathrm{X}$ antibodies (aSlex)-conjugated Poly(amidoamine) dendrimers. ${ }^{60}$ The conjugation was characterized by ultraviolet, atomic force microscope, and fluorescence measurements. The capture and regulation of colon cancer cells by the aSlex-coated dendrimer conjugate were examined by microscopy and flow cytometry. The conjugate showed improved capture of HT29 cells in a concentrationdependent manner, and the utmost capture competence was attained within 1 hour of exposure. The G6-5aSlex-FITC conjugate proved a better capture efficiency than FITC-G6COOH-5aSlex conjugate. In addition, the G6-5aSlex-FITC conjugate particularly captured HT29 cells, even after the target HT29 cells were diluted with the interfering cells to a low concentration. The capture resulted in a concentration-dependent control of cell activity. Consequently, the aSlex-coated dendrimer conjugate displayed immense potential in capturing and restraining colorectal CTCs in blood. ${ }^{60}$ Moreover, the study on regulation mechanism proved that the viability of captured CTCs declined in a modest concentration-dependent manner. This improved cell capture and regulation ability of conjugates allowed the design of new functionalized nanomaterials to capture and restrain CTCs in blood.

A sequence of telodendrimers, suspended with linear PEG-blocking dendritic oligomer of cholic acid and vitamin E, designed with architectures optimized for competent delivery of gambogic acid (GA) and other natural anticancer compounds have also been reported previously. ${ }^{58}$ Two of the telodendrimers with segregated cholic acid and vitamin $\mathrm{E}$ domains self-assembled into cylindrical or spherical NPs after being filled with GA as observed under TEM, which correlated with the dynamic light scattering analysis of sub-30 $\mathrm{nm}$ particle sizes. A high GA loading 
ability and constant drug release were obtained with the optimized telodendrimers. These novel nanoformulations of GA were established to display similar in vitro cytotoxic activity against colon cancer cells as the free drug. Near-infrared fluorescence small animal imaging showed favored accumulation of GA-loaded NPs into tumor tissue. Optimized nanoformulation of GA accomplished superior antitumor effectiveness compared with GA-Cremophor EL formulation at corresponding doses in HT-29 human colon cancer xenograft mouse models. ${ }^{58}$ Therefore, the moderate unfavorable effects linked with this natural compound and the improved anticancer effects via tumor-targeted telodendrimer delivery make this optimized GA nanoformulation a capable substitute to the traditional chemotherapy in colon cancer treatment. ${ }^{58}$ In 2014, researchers reported a new platform that was developed to re-engineer nanoscale dendrimers for the capture of CTCs in blood and to facilitate the adhesion of interfering CTCs to vascular endothelial bed to form micrometastatic foci. ${ }^{61}$ These nanoscale dendrimers were accommodated with dual antibodies to target two surface biomarkers of colorectal CTCs. The dual antibody conjugates were capable to particularly recognize and bind CTCs and reasonably down-regulate the activity of the captured CTCs by arresting cells in the $\mathrm{S}$ phase. The associated adhesion assay showed that the dual antibody conjugates obstructed the hetero-adhesion of CTCs to fibronectin (Fn)-coated substrates and human umbilical vein endothelial cells. Moreover, dual antibody conjugates demonstrated improved specificity and competence in restraining CTCs in vitro and in vivo in contrast to their single antibody counterparts. These observations revealed an innovative means of effectively preventing cancer metastatic initiation by binding and restraining CTCs and inhibiting their hetero-adhesion to blood vessels, but not by traditional cytotoxic-killing of cancer cells. ${ }^{61}$ A summary of different nanotechnological methods in the detection and treatment of CRC is presented in Table 4.

\section{Other NPs used in the detection and treatment of CTC}

Encapsulating chemotherapy drugs within targeted nanodelivery systems is a capable strategy to undertake cancer and avoid the adverse influences of conventional treatment. In the last 10 years, although numerous nanocarriers with diverse characteristics have been assessed, polypeptide-based copolymers have involved substantial consideration for their biocompatibility, controlled and slow biodegradability, and low toxicity. For example, researchers have formulated, characterized, and assessed poly(trimethylene carbonate)block-poly(L-glutamic acid) derived polymersomes, which were targeted to the EGFR, loaded with plitidepsin, and tested for specificity and efficacy in HT29 and LS174T CRC cell lines. ${ }^{62} \mathrm{~A}$ systematic in vitro cytotoxicity assessment of the unloaded polymersomes was carried out to determine viability, cell membrane asymmetry, biocompatibility check, and reactive oxygen species levels. These cytotoxicity assays established a fine biocompatibility for plitidepsin-unloaded polymersomes.

Table 4 Summary of nanotechnological methods in the detection and treatment of CRC

\begin{tabular}{|c|c|c|c|}
\hline Nanosystem & Structure & Characteristics & $\begin{array}{l}\text { Applications } \\
\text { in CRC }\end{array}$ \\
\hline QDs & $\begin{array}{l}\text { QDs are nanocrystals of a semiconducting material } \\
\text { with diameters in the range of } 2-10 \mathrm{~nm}\end{array}$ & $\begin{array}{l}\text { QDs have excellent optical properties, including high } \\
\text { brightness, resistance to photobleaching, and tunable } \\
\text { wavelength }\end{array}$ & $\begin{array}{l}\text { Detection and } \\
\text { treatment }\end{array}$ \\
\hline $\begin{array}{l}\text { Iron oxide } \\
\text { nanocrystals }\end{array}$ & $\begin{array}{l}\text { These are iron oxide particles with diameters } \\
\text { between about I and } 100 \mathrm{~nm}\end{array}$ & $\begin{array}{l}\text { They have attracted extensive interest due to their } \\
\text { superparamagnetic properties and their potential } \\
\text { applications in many fields }\end{array}$ & Detection \\
\hline $\begin{array}{l}\text { PLGA } \\
\text { nanoparticles/ } \\
\text { nanocells }\end{array}$ & $\begin{array}{l}\text { Different structures of PLGA copolymers with } \\
\text { various properties have been used in different drug } \\
\text { delivery systems }\end{array}$ & $\begin{array}{l}\text { PLGA is one of the most successfully used } \\
\text { biodegradable polymers because its hydrolysis leads } \\
\text { to metabolite monomers, lactic acid, and glycolic acid }\end{array}$ & $\begin{array}{l}\text { Detection and } \\
\text { therapy. Approved } \\
\text { by the US FDA }\end{array}$ \\
\hline Dendrimers & $\begin{array}{l}\text { These are radially emerging hyperbranched synthetic } \\
\text { polymers with regular pattern and repeated units }\end{array}$ & $\begin{array}{l}\text { These are repetitively branched molecules } \\
\text { characterized by structural perfection }\end{array}$ & $\begin{array}{l}\text { Detection and } \\
\text { treatment }\end{array}$ \\
\hline Liposomes & $\begin{array}{l}\text { These are self-assembling closed colloidal structures } \\
\text { composed of lipid biolayers }\end{array}$ & $\begin{array}{l}\text { Liposomes are artificially constructed vesicles } \\
\text { consisting of a phospholipid bilayer. Liposomes } \\
\text { are an effective way to transport water soluble } \\
\text { (hydrophilic) substances into or out of a cell }\end{array}$ & $\begin{array}{l}\text { Detection and } \\
\text { treatment }\end{array}$ \\
\hline $\begin{array}{l}\text { Gold } \\
\text { nanoshells }\end{array}$ & $\begin{array}{l}\text { Gold nanoshells are SPR nanoparticles consisting of } \\
\text { a nanoscale silica core surrounded by an ultra-thin } \\
\text { gold shell }\end{array}$ & $\begin{array}{l}\text { This class of plasmonic nanoparticles has a wide } \\
\text { variety of applications, including uses in optical filters, } \\
\text { sensing, and cancer therapy }\end{array}$ & $\begin{array}{l}\text { Detection and } \\
\text { treatment }\end{array}$ \\
\hline
\end{tabular}

Abbreviations: CRC, colorectal cancer; FDA, Food and Drug Administration; PLGA, polylactide-co-glycolic acid; QD, quantum dots; SPR, surface plasmon resonant. 
The cellular uptake and cytotoxic effect of EGFR-targeted plitidepsin-loaded polymersomes specified that the CRC cell lines were more sensitive to anti-EGFR drug-loaded than untargeted drug-loaded polymersomes. Additionally, the use of untargeted polymersomes reduced plitidepsin cytotoxicity and cellular uptake, indicating that the use of this targeted nanocarrier in both cell lines is a capable strategy to undertake CRC and avoid unwanted side effects of the normal treatment. ${ }^{62}$

Gold nanoshells or gold nanospheres have been studied over the past decade because of their inherent localized surface plasmon resonance. Altering the core size, gold shell thickness, and composition of the particles, the plasmomic resonance of gold nanospheres can have an absorbance ranging from the visible region of the spectrum to the nearinfrared region. Water and naturally occurring fluorochromes have the least absorption coefficient in the near-infrared region; consequently, light can penetrate deeper into the tissues. Gold nanospheres can also be conjugated with imaging reporters and carry drug payloads, genes, and other chemotherapeutic agents for theranostic applications. Although they can passively accumulate in tumors, gold nanospheres can be functionalized with active targeting ligands such as antibodies, Apts, and peptides to increase the specific binding of the particle to required targets. ${ }^{63}$

In another study, researchers described new near infrared fluorescent proteinoid-poly(L-lactic acid) (PLLA) NPs preparation. ${ }^{64}$ Here they prepared a $\mathrm{P}$ (EF-PLLA) random copolymer by thermal copolymerization of L-glutamic acid (E) with L-phenylalanine (F) and PLLA. ${ }^{64}$ Under optimal conditions, this proteinoid-PLLA copolymer can self-assemble into hollow nanosized particles and was used to encapsulate the NIR dye, indocyanine green. The encapsulation process increased the photostability of the dye, and these near-infrared fluorescent NPs were steady and nontoxic. There was no detectable leakage of the near-infrared dye from these NPs into phosphate-buffered saline containing human serum albumin. Tumor-targeting ligands, such as peanut agglutinin and antiCEA antibodies, were covalently conjugated to the surface of the near-infrared fluorescent P (EF-PLLA) NPs, thereby increasing the detectable fluorescent signal from tumors with the corresponding up-regulated receptors. Specific colon tumor detection by the near-infrared fluorescent P (EF-PLLA) NPs has been demonstrated in a chicken embryo model. ${ }^{64}$

\section{Combinatorial nanomedicines for CRC therapy}

Nanomedicine has an incredible potential for revolutionizing the therapeutics and diagnostics under the premise of developing ingenious nanodevices. Researchers reported multidrug delivery using NPs to mediate resistance in relapsing cancers and to improve cancer treatment efficacy. ${ }^{65,66}$ Recently, a research group focused on an effective strategy to improve the efficacy of 5-FU-assisted chemotherapy against colon cancer. ${ }^{65}$ This has been managed by combinatorial strategy in which CRC was used in combination with 5-FU. ${ }^{65}$ The potential of both the drugs was enhanced by nanoencapsulation, in which a nontoxic polymeric carrier system "thiolated chitosan" was used. In this study, the enhanced anticancer effects of combinatorial nanomedicine are advantageous in terms of decrease in the dosage of 5-FU, thereby enhancing the chemotherapeutic efficacy and patient compliance of CRC cases. The nanosized drug-encapsulated systems are advantageous in terms of passive targeting, which helps in the retention of more drug-loaded NPs into tumors through enhanced permeability and retention effect (Figure 2). These exciting strategies have served as a base for the next phase of cancer nanomedicine in the clinic. ${ }^{65,67-70}$

\section{Future prospective}

Nanoscience applied to cancer research is proving to be a critical and encouraging approach for the eventual elimination or at least chronic control of cancer. Nanotechnology has been making a significant impact on cancer diagnosis and therapeutic management in revolutionary ways. The development of drug delivery systems that are able to modify the biodistribution, tissue uptake, and pharmacokinetics of therapeutic agents is considered to be of immense importance in biomedical research. Controlled release drug delivery can considerably increase the therapeutic consequence of a drug. The striking properties of nanomedicines include their capability to controlled release of drugs, targeting of definite tissues, and biocompatibility. Because of their minute size, NPs can be taken up very efficiently by cells forming a constant nanocomplex, thereby defending it from nuclease degradation and allowing successful delivery to the tumor site. In spite of the challenges restricting its application, it is promising that nanomedicine in future would play a critical role in the detection and treatment of human $\mathrm{CRC}$, and also in the improvement of normal human physiology.

\section{Conclusion}

Recently, there has been an increased focus on developing novel drug delivery systems, targeted therapies, and medical devices, including the use of nanotechnology and nanomaterials. This focus is translating to increase in vitro diagnostics through a number of submissions for drug products 


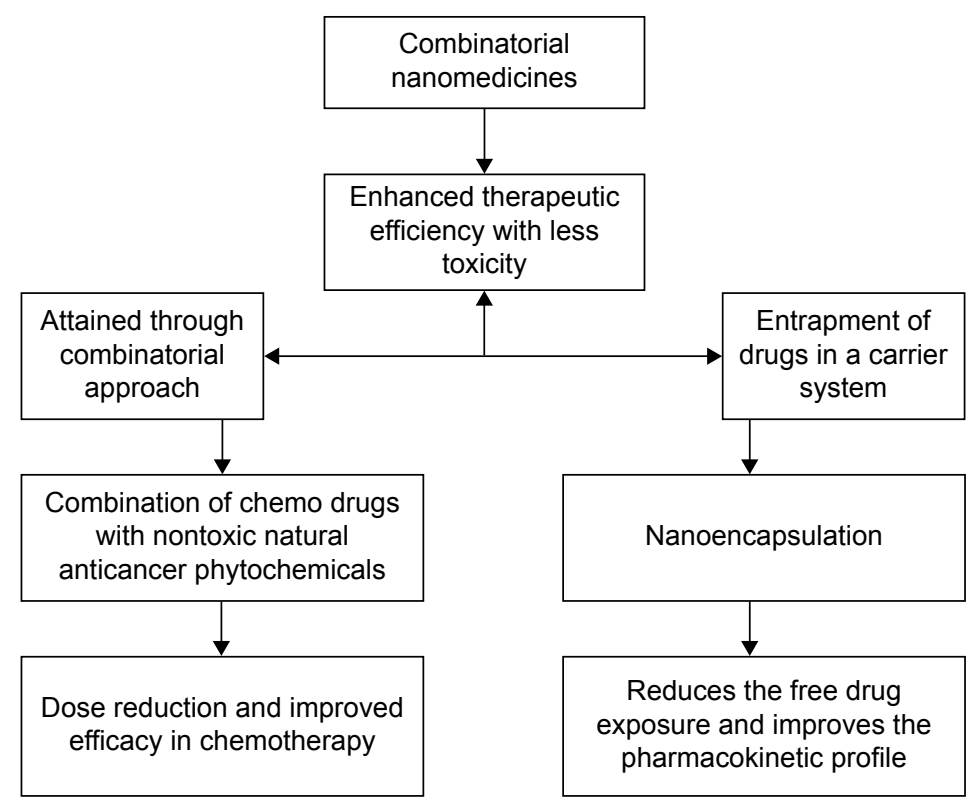

Figure 2 Schematic representation of the advantages of combinatorial nanomedicines in CRC.

and medical devices to the Food and Drug Administration. Although subject to the similar regulatory principles and pathways as any other drug or device, the unique properties that arise from the small-sized and large surface area of nanomaterials may lead to further scientific considerations when following the present guidelines and practices of the Food and Drug Administration. Nanotechnology may enable medical products to develop beyond a single mode of action into multifunctional platforms performing several functions such as nanotheranostics that combines therapeutics with diagnostics. Researchers from around the globe are actively incorporating nanotechnology in CRC treatment. Preclinical characterization of nanomaterials has shown considerable advancement over the last decade. Methods are being developed and optimized continually in order to meet the needs of the evolving complexity of nanomedicines. Detailed NP surface characterization, predictive immunotoxicity assays, and quantitative evaluation of the encapsulated versus free drug fractions highlight the growth of this field. The pursuit for the development of new methods and conducting research directed at understanding the nano-bio interface will uncover additional relationships between NP structure and biological activity. This information will be invaluable in devising new strategies for using nanotechnology to improve upon the existing pharmaceuticals and deliver novel therapies in future.

\section{Acknowledgment}

This research was supported by the R\&D Program for Society of the National Research Foundation funded by the Ministry of Science, ICT \& Future Planning (2013M3C8A3078806 and 2015M3A9E2031372).

\section{Disclosure}

The authors report no conflicts of interest in this work.

\section{References}

1. da Paz MC, Santos Mde F, Santos CM, et al. Anti-CEA loaded maghemite nanoparticles as a theragnostic device for colorectal cancer. Int J Nanomedicine. 2012;7:5271-5282.

2. Arvelo F, Sojo F, Cotte C. Biology of colorectal cancer. Ecancermedicalscience. 2015;9:520.

3. Bours MJ, Beijer S, Winkels RM, et al. Dietary changes and dietary supplement use, and underlying motives for these habits reported by colorectal cancer survivors of the Patient Reported Outcomes Following Initial Treatment and Long-Term Evaluation of Survivorship (PROFILES) registry. Br J Nutr. 2015;114(2):286-296.

4. Gulbake A, Jain A, Jain A, Jain A, Jain SK. Insight to drug delivery aspects for colorectal cancer. World J Gastroenterol. 2016;22(2): 582-599.

5. Datta K, Suman S, Kumar S, Fornace AJ Jr. Colorectal carcinogenesis, radiation quality, and the ubiquitin-proteasome pathway. J Cancer. 2016; $7(2): 174-183$

6. Kheirelseid E, Miller N, Kerin M. Molecular biology of colorectal cancer: review of the literature. Am J Mol Biol. 2013;3:72-80.

7. Hutchinson, Adams RA, McArt DG, Salto-Tellez M, Jasani B, Hamilton PW. Epidermal growth factor receptor immunohistochemistry: new opportunities in metastatic colorectal cancer. J Transl Med. 2015;13:217.

8. Valle I, Tramalloni D, Bragazzi NL. Cancer prevention: state of the art and future prospects. J Prev Med Hyg. 2015;56(1):E21-E27.

9. Schroy PC, Duhovic E, Chen CA, et al. Risk. Stratification and shared decision making for colorectal cancer screening: a randomized controlled trial. Med Decis Making. 2016;36(4):526-535.

10. Lai Y, Wang C, Civan JM, et al. Effects of cancer stage and treatment differences on racial disparities in survival from colon cancer: a United States population-based study. Gastroenterology. 2016; 150(5):1135-1146. 
11. Xynos ID, Kavantzas N, Tsaousi S, et al. Factors influencing survival in stage IV colorectal cancer: the influence of DNA ploidy. ISRN Gastroenterol. 2013;2013:490578.

12. Pesta M, Kulda V, Narsanska A, Fichtl J, Topolcan O. May CTC technologies promote better cancer management? EPMA J. 2015; 6(1):1.

13. Young PE, Womeldorph CM, Johnson EK, et al. Early detection of colorectal cancer recurrence in patients undergoing surgery with curative intent: current status and challenges. J Cancer. 2014;5(4): 262-271.

14. Zhou Y, Wang H, Gong H, Cao M, Zhang G, Wang Y. Clinical significance of perineural invasion in stages II and III colorectal cancer. Pathol Res Pract. 2015;211(11):839-844.

15. Bhatt A, Goéré D. Cytoreductive surgery plus HIPEC for peritoneal metastases from colorectal cancer. Indian J Surg Oncol. 2016;7(2): 177-187.

16. Sun Y, Liu Y, Cogdell D, et al. Examining plasma microRNA markers for colorectal cancer at different stages. Oncotarget. 2016;7(10): 11434-11449.

17. Kahi CJ, Boland CR, Dominitz JA, et al. Colonoscopy surveillance after colorectal cancer resection: recommendations of the US multi-society task force on colorectal cancer. Am J Gastroenterol. 2016;111(3): 337-346.

18. Kuipers EJ, Spaander MC. Colorectal cancer screening by colonoscopy, CT-colonography, or fecal immunochemical test. J Natl Cancer Inst. 2015;108(2):pii.djv383.

19. Guo C, Liu Q, Dai M. Colorectal cancer screening: situation and prospect. Zhonghua Yu Fang Yi Xue Za Zhi. 2015;49(5):377-380.

20. Allen JE, Saroya BS, Kunkel M, et al. Apoptotic circulating tumor cells (CTCs) in the peripheral blood of metastatic colorectal cancer patients are associated with liver metastasis but not CTCs. Oncotarget. 2014;5(7):1753-1760.

21. Mostert B, Sieuwerts AM, Bolt-de Vries J, et al. mRNA expression profiles in circulating tumor cells of metastatic colorectal cancer patients Mol Oncol. 2015;9(4):920-932.

22. Young GP, Senore C, Mandel JS, et al. Recommendations for a stepwise comparative approach to the evaluation of new screening tests for colorectal cancer. Cancer. 2016;122(6):826-839.

23. Chu E. An update on the current and emerging targeted agents in metastatic colorectal cancer. Clin Colorectal Cancer. 2012;11:1-13.

24. Lee SW. Laparoscopic procedures for colon and rectal cancer surgery. Clin Colon Rectal Surg. 2009;22:218-224.

25. Joye I, Haustermans K. Early and late toxicity of radiotherapy for rectal cancer. In: Otto F, Lutz MP, editors. Early Gastrointestinal Cancers II: Rectal Cancer. Switzerland: Springer International Publishing; 2014:189-201.

26. Jayakumar J, Mohammed ZH, Jayaprakash BU, Ramzi MM, Bhat AA. Recent developments in nanomedicine; treatment options for colorectal cancer. In: Macha MA, editor. Modern Technology: Present and Future of Cancer. CA, USA: OMICS Group eBooks; 2015.

27. Strebhardt K, Ullrich A. Paul Ehrlich's magic bullet concept: 100 years of progress. Nat Rev Cancer. 2008;8(6):473-480.

28. Bertrand N, Wu J, Xu X, Kamaly N, Farokhzad OC. Cancer nanotechnology: the impact of passive and active targeting in the era of modern cancer biology. Adv Drug Deliv Rev. 2014;66:2-25.

29. Laroui H, Rakhya P, Xiao B, Viennois E, Merlin D. Nanotechnology in diagnostics and therapeutics for gastrointestinal disorders. Dig Liver Dis. 2013;45(12):995-1002.

30. Dong Z, Cui MY, Peng Z, et al. Nanoparticles for colorectal cancertargeted drug delivery and MR imaging: current situation and perspectives. Curr Cancer Drug Targets. Epub 2015 Nov 30.

31. Fang M, Peng CW, Pang DW, Li Y. Quantum dots for cancer research: current status, remaining issues, and future perspectives. Cancer Biol Med. 2012;9(3):151-163.

32. Pericleous P, Gazouli M, Lyberopoulou A, Rizos S, Nikiteas N, Efstathopoulos EP. Quantum dots hold promise for early cancer imaging and detection. Int J Cancer. 2012;131(3):519-528.
33. Zeng WJ, Peng CW, Yuan JP, Cui R, Li Y. Quantum dot-based multiplexed imaging in malignant ascites: a new model for malignant ascites classification. Int J Nanomedicine. 2015;10:1759-1768.

34. Wang S, Li W, Yuan D, Song J, Fang J. Quantitative detection of the tumor-associated antigen large external antigen in colorectal cancer tissues and cells using quantum dot probe. Int J Nanomedicine. 2016; $12: 235-247$

35. Wang Y, Li Y, Wang T, Gu J, Zhao J, Pan Z. Detection of AKR1B10 in peripheral blood by anti-AKR1B10-conjugated $\mathrm{CdTe} / \mathrm{CdS}$ quantum dots. Clin Lab. 2015;61(9):1267-1274.

36. Carbary-Ganz JL, Welge WA, Barton JK, Utzinger U. In vivo molecular imaging of colorectal cancer using quantum dots targeted to vascular endothelial growth factor receptor 2 and optical coherence tomography/ laser-induced fluorescence dual-modality imaging. J Biomed Opt. 2015;20(9):096015

37. Xing X, Zhang B, Wang X, Liu F, Shi D, Cheng Y. An “imagingbiopsy" strategy for colorectal tumor reconfirmation by multipurpose paramagnetic quantum dots. Biomaterials. 2015;48:16-25.

38. Gazouli M, Bouziotis P, Lyberopoulou A, etal. Quantum dots-bevacizumab complexes for in vivo imaging of tumors. In Vivo. 2014;28(6): 1091-1095.

39. Carbary-Ganz JL, Barton JK, Utzinger U. Quantum dots targeted to vascular endothelial growth factor receptor 2 as a contrast agent for the detection of colorectal cancer. J Biomed Opt. 2014;19(8):086003.

40. Li WM, Bing T, Wei JY, Chen ZZ, Shangguan DH, Fang J. CellSELEX-based selection of aptamers that recognize distinct targets on metastatic colorectal cancer cells. Biomaterials. 2014;35(25): 6998-7007.

41. Espinosa A, Di Corato R, Kolosnjaj-Tabi J, Flaud P, Pellegrino T, Wilhelm C. Duality of iron oxide nanoparticles in cancer therapy: amplification of heating efficiency by magnetic hyperthermia and photothermal bimodal treatment. ACS Nano. 2016;10(2):2436-2446.

42. Kuo CY, Liu TY, Chan TY, et al. Magnetically triggered nanovehicles for controlled drug release as a colorectal cancer therapy. Colloids Surf B Biointerfaces. 2016;140:567-573.

43. Esmaelbeygi E, Khoei S, Khoee S, Eynali S. Role of iron oxide core of polymeric nanoparticles in the thermosensitivity of colon cancer cell line HT-29. Int J Hyperthermia. 2015;31(5):489-497.

44. Yang CC, Yang SY, Ho CS, Chang JF, Liu BH, Huang KW. Development of antibody functionalized magnetic nanoparticles for the immunoassay of carcinoembryonic antigen: a feasibility study for clinical use. J Nanobiotechnology. 2014;12:44.

45. Feng ST, Li J, Luo Y, et al. pH-sensitive nanomicelles for controlled and efficient drug delivery to human colorectal carcinoma LoVo cells. PLoS One. 2014;9(6):e100732.

46. Mannucci S, Ghin L, Conti G, et al. Magnetic nanoparticles from Magnetospirillum gryphiswaldense increase the efficacy of thermotherapy in a model of colon carcinoma. PLoS One. 2014;9(10): e108959.

47. He X, Liu F, Liu L, Duan T, Zhang H, Wang Z. Lectin-conjugated Fe2O3@Au core@Shell nanoparticles as dual mode contrast agents for in vivo detection of tumor. Mol Pharm. 2014;11(3):738-745.

48. Sah H, Thoma LA, Desu HR, Sah E, Wood GC. Concepts and practices used to develop functional PLGA-based nanoparticulate systems. Int J Nanomedicine. 2013;8:747-765.

49. Akl MA, Kartal-Hodzica A, Oksanen T, et al. Factorial design formulation optimization and in vitro characterization of curcumin-loaded PLGA nanoparticles for colon delivery. J Drug Deliv Sci Technol. 2016;32(A): 10-20.

50. Tummala S, Satish Kumar MN, Prakash A. Formulation and characterization of 5-Fluorouracil enteric coated nanoparticles for sustained and localized release in treating colorectal cancer. Saudi Pharm J. 2015;23(3):308-314.

51. Essa S, Daoud J, Lafleur M, Martel S, Tabrizian M. SN-38 active loading in poly(lactic-co-glycolic acid) nanoparticles and assessment of their anticancer properties on COLO-205 human colon adenocarcinoma cells. J Microencapsul. 2015;32(8):784-793. 
52. Trif M, Florian PE, Roseanu A, et al. Cytotoxicity and intracellular fate of PLGA and chitosan-coated PLGA nanoparticles in Madin-Darby bovine kidney (MDBK) and human colorectal adenocarcinoma (Colo 205) cells. J Biomed Mater Res A. 2015;103(11):3599-3611.

53. Tang Q, Wang Y, Huang R, et al. Preparation of anti-tumor nanoparticle and its inhibition to peritoneal dissemination of colon cancer. PLoS One. 2014;9(6):e98455.

54. Klippstein R, Wang JT, El-Gogary R, et al. Passively targeted curcuminloaded PEGylated PLGA nanocapsules for colon cancer therapy in vivo. Small. 2015;11(36):4704-4722.

55. Li L, Xiang D, Shigdar S, et al. Epithelial cell adhesion molecule aptamer functionalized PLGA-lecithin-curcumin-PEG nanoparticles for targeted drug delivery to human colorectal adenocarcinoma cells. Int J Nanomedicine. 2014;9:1083-1096.

56. Wu LP, Ficker M, Christensen JB, Trohopoulos PN, Moghimi SM. Dendrimers in medicine: therapeutic concepts and pharmaceutical challenges. Bioconjug Chem. 2015;26(7):1198-1211.

57. Abbasi E, Aval SF, Akbarzadeh A, et al. Dendrimers: synthesis, applications, and properties. Nanoscale Res Lett. 2014;9(1):247.

58. Huang W, Wang X, Shi C, et al. Fine-tuning vitamin E-containing telodendrimers for efficient delivery of gambogic acid in colon cancer treatment. Mol Pharm. 2015;12(4):1216-1229.

59. Xie J, Gao Y, Zhao R, et al. Ex vivo and in vivo capture and deactivation of circulating tumor cells by dual-antibody-coated nanomaterials. J Control Release. 2015;209:159-169.

60. Xie J, Wang J, Chen H, et al. Multivalent conjugation of antibody to dendrimers for the enhanced capture and regulation on colon cancer cells. Sci Rep. 2015;5:9445.

61. Xie J, Zhao R, Gu S, et al. The architecture and biological function of dual antibody-coated dendrimers: enhanced control of circulating tumor cells and their hetero-adhesion to endothelial cells for metastasis prevention. Theranostics. 2014;4(12):1250-1263.

62. Goñi-de-Cerio F, Thevenot J, Oliveira H, et al. Cellular uptake and cytotoxic effect of epidermal growth factor receptor targeted and plitidepsin loaded co-polymeric polymersomes on colorectal cancer cell lines. J Biomed Nanotechnol. 2015;11(11):2034-2049.
63. Singhana B, Slattery P, Melancon MP. Targeted gold Nanoshells. In: Hamblin MR, Avci P, editors. Applications of Nanoscience in Photomedicine. Oxfordshire, United Kingdom: Woodhead Publishing Limited-Chandos Publishing; 2015:267-290.

64. Kolitz-Domb M, Corem-Salkmon E, Grinberg I, Margel S. Synthesis and characterization of bioactive conjugated near-infrared fluorescent proteinoid-poly(L-lactic acid) hollow nanoparticles for optical detection of colon cancer. Int J Nanomedicine. 2014;9:5041-5053.

65. Anitha A, Maya S, Sivaram AJ, Mony U, Jayakumar R. Combinatorial nanomedicines for colon cancer therapy. Wiley Interdiscip Rev Nanomed Nanobiotechnol. 2016;8(1):151-159.

66. Maya S, Sarmento B, Lakshmanan VK, Menon D, Jayakumar R. Actively targeted cetuximab conjugated gamma-poly(glutamic acid)-docetaxel nanomedicines for epidermal growth factor receptor over expressing colon cancer cells. J Biomed Nanotechnol. 2014;10(8):1416-1428.

67. Malarvizhi GL, Retnakumari AP, Nair S, Koyakutty M. Transferrin targeted core-shell nanomedicine for combinatorial delivery of doxorubicin and sorafenib against hepatocellular carcinoma. Nanomedicine. 2014;10(8):1649-1659.

68. Linton SS, Sherwood SG, Drews KC, Kester M. Targeting cancer cells in the tumor microenvironment: opportunities and challenges in combinatorial nanomedicine. Wiley Interdiscip Rev Nanomed Nanobiotechnol. 2016;8(2):208-222.

69. Anitha A, Deepa N, Chennazhi KP, Lakshmanan VK, Jayakumar R. Combinatorial anticancer effects of curcumin and 5-fluorouracil loaded thiolated chitosan nanoparticles towards colon cancer treatment. Biochim Biophys Acta. 2014;1840(9):2730-2743.

70. Anitha A, Sreeranganathan M, Chennazhi KP, Lakshmanan VK, Jayakumar R. In vitro combinatorial anticancer effects of 5-fluorouracil and curcumin loaded N,O-carboxymethyl chitosan nanoparticles toward colon cancer and in vivo pharmacokinetic studies. Eur J Pharm Biopharm. 2014;88(1):238-251.
International Journal of Nanomedicine

\section{Publish your work in this journal}

The International Journal of Nanomedicine is an international, peerreviewed journal focusing on the application of nanotechnology in diagnostics, therapeutics, and drug delivery systems throughout the biomedical field. This journal is indexed on PubMed Central,

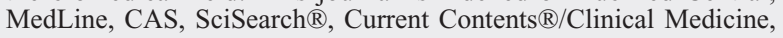

\section{Dovepress}

Journal Citation Reports/Science Edition, EMBase, Scopus and the Elsevier Bibliographic databases. The manuscript management system is completely online and includes a very quick and fair peer-review system, which is all easy to use. Visit http://www.dovepress.com/ testimonials.php to read real quotes from published authors. 